\title{
UNA ESPECIE NUEVA DEL GÉNERO ASTROCASIA (EUPHORBIACEAE) DEL ESTADO DE GUERRERO, MÉXICO
}

\author{
JaIME JimÉnEZ RAmíREZ \\ Y \\ Martha Martínez Gordillo \\ Herbario de la Facultad de Ciencias, UNAM \\ Apartado postal 70-399 \\ 04510 México, D.F.
}

\begin{abstract}
RESUMEN
Se describe e ilustra Astrocasia diegoae, una nueva especie del estado de Guerrero, México. Este nuevo taxon se distingue de las restantes cinco especies conocidas de Astrocasia por ser un sufrútice monoico, con flores de sépalos y pétalos casi del mismo tamaño y ocasionalmente inflorescencias bisexuales. El género Astrocasia ha sido considerado esencialmente como constituido por plantas dioicas, pero esta nueva especie y la existencia de especímenes monoicos de $A$. neurocarpa en Guerrero modifican tal concepto. Se menciona a Astrocasia neurocarpa como registro nuevo para el estado de Guerrero y se incluye una clave para identificar a las especies del género que se encuentran en México.
\end{abstract}

Palabras clave: Astrocasia, Euphorbiaceae, Guerrero, México.

\begin{abstract}
Astrocasia diegoae, a new species from Guerrero, Mexico, is described and illustrated. This new taxon is distinguished from the other five known species of Astrocasia in being a monoecious subshrub, having the sepals and petals of almost the same size, and occasionally possessing bisexual inflorescences. A key is provided for the identification of the four species of Astrocasia known from Mexico. Astrocasia neurocarpa is reported for the first time from the state of Guerrero. Although the genus Astrocasia has been considered essentially dioecious, this notion is altered by the existence of this new monoecious species, as well as the presence of monoecious individuals of $A$. neurocarpa in Guerrero.
\end{abstract}

Key words: Astrocasia, Euphorbiaceae, Guerrero, Mexico.

Astrocasia Rob. et Millsp. es un género americano de cinco especies conocidas, más la ahora descrita, que se distribuye principalmente en México y las Antillas, aunque una se conoce de Brasil y Bolivia (Webster, 1992). Para la República Mexicana se registran ahora cuatro representantes: Astrocasia diegoae sp. nov., A. neurocarpa (Müll. Arg.) I. M. 
Johnst., A. tremula (Griseb.) G. L. Webster y A. peltata Standl. Se distingue de Phyllanthus principalmente por la presencia de la corola en ambos tipos de flores. En este trabajo se describe una especie nueva del estado de Guerrero, México, que se caracteriza por ser un sufrútice monoico, tener los pétalos casi del mismo tamaño que los sépalos y los glomérulos en ocasiones bisexuales.

Astrocasia diegoae J. Jiménez Ram. et Gordillo sp. nov. Fig. 1.

Suffrutex 40-60 cm altus, monoecius. Folia 4-12 mm longa, 2.5-6 mm lata, ovata, subpeltata, apice rotundato, emarginato, margine integra, base acuta; petiolus 1-2 mm longus, stipulae ovatae, caducae. Inflorescentiae in fasciculis in axillis foliorum ortis vel in brachyblastis, unisexuales interdum bisexuales. Flores masculi pedicellati, sepala 5, ovata, petala 5, calyce vix longiora; stamina 5, filamenta connata. Flores feminei pedicellati, sepala 5, petala 5. Capsula 3.5-4 $\mathrm{mm}$ diametro.

Sufrútices, 40-60 cm de alto, glabros, monoicos. Hojas 4-12 x 2.5-6 mm, ovadas, subpeltadas, puberulentas, ápice redondeado, emarginado, margen entero, base redondeada con 3 venas poco conspicuas en la base, nervación inconspicua, haz y envés glabros; pecíolo 1-2 $\mathrm{mm}$ de largo; estípulas $1-1.3 \mathrm{~mm}$ de largo, 0.6-0.8 $\mathrm{mm}$ de ancho, ovadas, caducas. Inflorescencias en forma de fascículos, que surgen en las axilas de las hojas o en braquiblastos, unisexuales, con 1-4 flores estaminadas u ocasionalmente bisexuales con una flor pistilada adicional, estas últimas con frecuencia solitarias. Flores estaminadas pediceladas, pedicelo 1.5-4 mm de largo; sépalos 5, 0.6-2 x 0.5-0.8 mm, ovados, glabros en ambas caras; pétalos 5, ligeramente más largos que los sépalos, espatulados; disco presente, representado por 5 glándulas oblatas; estambres 5 , filamentos connados en una columna de 0.5-0.7 mm de largo, anteras 0.5-0.8 mm de largo, subsésiles en el ápice de la misma, horizontales. Flores pistiladas pediceladas, pedicelos 4-10 mm de largo; sépalos 5 , ovados; pétalos 5 , casi del mismo tamaño que los sépalos; disco presente; ovario casi esférico, glabro, estilos 3, bífidos, glabros. Fruto en cápsula $3.5-4 \mathrm{~mm}$ de diámetro, subglobosa; columela persistente. Semillas desconocidas.

TIPO: México, Guerrero, municipio Mártir de Cuilapan, reserva campesina La Esperanza, orilla del camino en suelos arcillosos, 3-V-1997, N. Diego y B. González 7250, (Holotipo: FCME, Isotipo: MEXU).

Material adicional revisado: México, Guerrero, municipio Eduardo Neri, Barranca de Acatitlán, $17^{\circ} 50^{\prime} \mathrm{N}, 9^{\circ} 36^{\prime} \mathrm{O}$, alt. $1020 \mathrm{~m}, 27-\mathrm{X}-1990$. M. Gual y C. Villegas 207 (FCME).

Florece y fructifica de mayo a octubre. Crece en suelos pedregosos con humus. Puede distinguirse fácilmente del resto de las especies del género por ser un sufrútice monoico, por el reducido tamaño de sus hojas y el tamaño similar de los sépalos y los pétalos.

Es importante apuntar que además de esta nueva especie, ocasionalmente también se han registrado individuos monoicos en Astrocasia tremula (Webster, 1992) y $A$. 


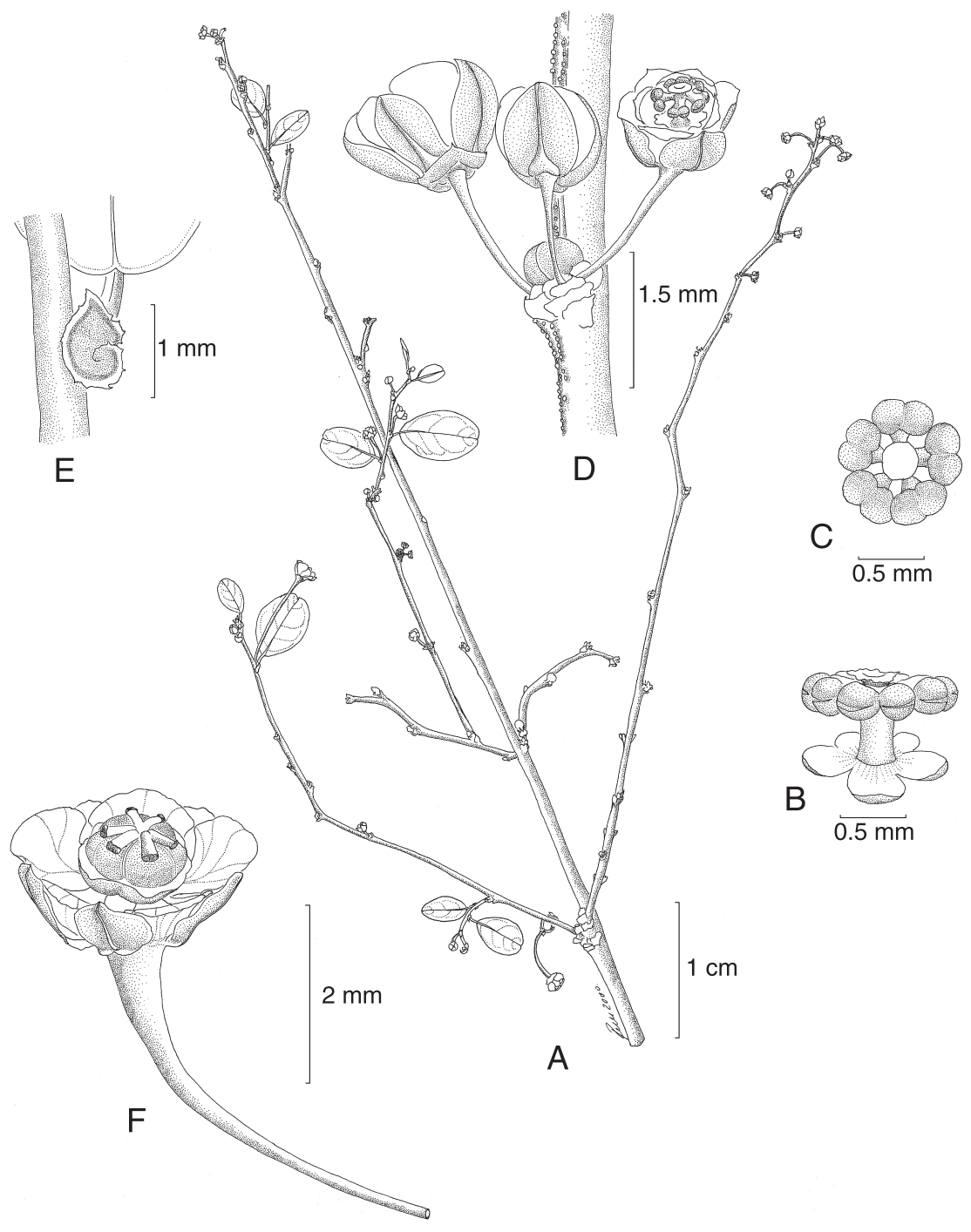

Fig. 1. Astrocasia diegoae Jiménez Ram. et Gordillo. A. Rama con flores; B. Androceo con disco basal, vista lateral; C. Androceo, vista dorsal; D. Fascículo de flores masculinas; E. Estípula; F. Flor femenina (N. Diego y B. González 7250). 
neurocarpa en los ejemplares Martínez 496 (FCME) y Jiménez 918, 919 y 920 (FCME) de Guerrero, siendo éstos los primeros registros del último taxon para el estado. A continuación se presenta una clave para las especies mexicanas de Astrocasia.

1 Sufrútices, monoicos; lámina foliar de 0.4-1.2 x 0.25-0.6 cm; pecíolo 0.1-0.2 cm de largo; sépalos y pétalos de tamaño similar A. diegoae

1 Árboles o arbustos dioicos u ocasionalmente monoicos; lámina foliar de $1.5 \mathrm{~cm}$ o más de largo y $1.5 \mathrm{~cm}$ o más de ancho; pecíolo $0.8-6 \mathrm{~cm}$ de largo; pétalos conspicuamente más grandes que los sépalos.

2 Hojas maduras conspicuamente peltadas

A. peltata

2 Hojas maduras con la unión pecíolo-limbo basal, en ocasiones en $A$. tremula muy estrechamente peltadas.

3 Lámina foliar 5-13 x 2.5-9 cm; con 5-9 pares de venas; pétalos de la flor pistilada 1.5-4.2 $\mathrm{mm}$ de largo; pétalos de la flor estaminada $2.5-3.5 \mathrm{~mm}$ de largo

A. tremula

3 Lámina foliar (1-)1.5-5(-7.7) x (0.8-)1.5-3.5(-6.5) cm, con 4-5 pares de venas; pétalos de la flor pistilada 3-3.7 mm de largo; pétalos de las flores estaminadas 2-2.5 mm de largo

A. neurocarpa

El género Astrocasia se considera que está esencialmente constituido por plantas dioicas, con la excepción de $A$. tremula, pero el hallazgo de la especie monoica, $A$. diegoae, y de individuos monoicos de $A$. neurocarpa alteran sensiblemente este concepto tradicional. Webster (1992) señala que existe una "dioecia modular" en $A$. tremula, ya que las ramas del mismo individuo sólo portan flores pistiladas o flores estaminadas; algo similar sucede en individuos de $A$. neurocarpa de Guerrero, donde surgen primero las flores estaminadas en las yemas axilares de las hojas caducas y después en ramas diferentes aparecen las flores pistiladas al tiempo del desarrollo de las ramas y hojas de la estación; durante un breve período las flores estaminadas y las pistiladas conviven y al final quedan sólo los frutos.

La población de $A$. neurocarpa de Guerrero habita en bosque tropical caducifolio en las cercanías de Tlapehualapa, dentro de la porción oriental de la Cuenca del Río Balsas a $1300 \mathrm{~m}$ de altitud y curiosamente está asociada a individuos enanos (3-4 m) de Bernoullia flammea, planta típica de bosque tropical perennifolio o bosque tropical subcaducifolio, por lo que las condiciones de humedad del lugar deben ser relativamente altas. En contraste, los registros de la especie del norte de México indican condiciones mucho más secas, propias de matorral xerófilo. Resultaría interesante indagar si estos individuos son realmente dioicos y eventualmente correlacionar al hábitat con la expresión del sexo en las diversas poblaciones.

Finalmente, en el caso de $A$. diegoae la monoecia es un rasgo distintivo de la especie con la notable peculiaridad de que algunas inflorescencias portan flores pistiladas y estaminadas simultáneamente.

El nombre del taxon nuevo se dedica a la maestra Nelly Diego, quien por largos años ha estudiado la flora de Guerrero. 
Jiménez y Martínez: Una Especie Nueva del Género Astrocasia de Guerrero, México

\section{AGRADECIMIENTOS}

Se agradece al Biólogo Ramiro Cruz Durán por la elaboración de la ilustración.

\section{LITERATURA CITADA}

Webster, G. L. 1992. Revision of Astrocasia (Euphorbiaceae). Systematic Botany 17(2): 311-323.

Recibido en noviembre de 2000. Aceptado en julio de 2001. 